"State-dependent risk taking and the transmission of monetary policy shocks"

Patric Fève, Pablo Garcia and Jean-Guillaume Sahuc 


\title{
STATE-DEPENDENT RISK TAKING AND THE TRANSMISSION OF MONETARY POLICY SHOCKS
}

\author{
PATRICK FÈVE, PABLO GARCIA AND JEAN-GUILLAUME SAHUC
}

\begin{abstract}
Is risk taking an important channel by which monetary policy shocks affect economic activity? On the basis of a nonlinear structural VAR including a new measure of risk sensitivity by economic agents, we show that the role of the risk-taking channel depends on the state of the economy. While it is irrelevant during recession or normal times, it acts as an amplifier by boosting output during expansion. It means that, as long as monetary policy does not actively "lean against the wind", it may exacerbate boom-bust patterns.
\end{abstract}

JEL: C32, E52.

Keywords: Risk-taking channel, Monetary policy, Boom-bust cycle

\section{INTRODUCTION}

In the wake of the recent global financial crisis, the relationship between monetary policy and the risk appetite of economic agents has been pointed out. Market observers have claimed that the prolonged period of low interest rates under favorable economic and financial conditions in the early 2000s might have produced overconfidence by economic agents, (i) increasing dramatically their risk tolerance and (ii) contributing to financial imbalances. This mechanism, called the risk-taking channel of monetary policy, can have long lasting adverse consequences on economic activity if it is neglected (see Borio and Zhu (2012) and Diamond and Rajan (2012), among others).

The aim of this paper is to investigate the importance of the risk-taking channel in the propagation of monetary policy shocks to the US economy. To this end, we build an indicator of risk sensitivity and introducing it together with output and a measure of the monetary policy stance in a logistic vector smooth transition autoregressive model (LVSTAR, Terasvirta et al. (2010)). Using a standard identification scheme for monetary policy shocks (Christiano et al., 1999), we find that the role of the risk-taking channel depends on the state of the economy. During recession or normal times, it has a small effect on the transmission of monetary policy shocks to economic activity. However, during economic booms the risk-taking channel acts as an amplifier by boosting output. Excessive risk appetites may potentially lead to boom-bust patterns. Central banks

October 2017. P. Fève (corresponding author): TSE-Université de Toulouse 1-Capitole, Manufacture des Tabacs, bat. F, 21 allée de Brienne, 31000 Toulouse, France (e-mail: patrick.feve@tse-fr.eu). P. Garcia: TSE-Université de Toulouse 1-Capitole, Manufacture des Tabacs, bat. F, 21 allée de Brienne, 31000 Toulouse, France. J.-G. Sahuc: Banque de France, 31 rue Croix des Petits Champs, 75049 Paris, France. The views expressed in this paper are those of the authors and should under no circumstances be interpreted as reflecting those of the Banque de France or the Eurosystem. 
should then account for this channel when adjusting their policy in order to mitigate the adverse consequence of their decisions on economic activity.

\section{MEASURING RISK TAKING}

As pointed out by Borio and Zhu (2012), usual market-based indicators of risk, such as interest rates and risk premia, are often low just before the peak of the financial cycle, when in retrospect, it transpires that risk was at its highest. Then, we need to capture the resilience of the overall financial system, that crucially depends on the underlying health of all sectors of the economy (Hatzius et al., 2010). First, lending to households has taken a central role in the balance sheets of financial intermediaries. Therefore, taking into account both the solvency and liquidity position of the household outperforms the most common metrics used in the literature (Tullio et al. (2013) and Ampudia et al. (2016)). Second, highly leveraged firms may enter in financial distress during a crisis, exacerbating cutbacks in investment and employment and contributing to the persistence of the downturn (Bernstein et al. (2017)).

Figure 1. A Risk Sensitivity Indicator

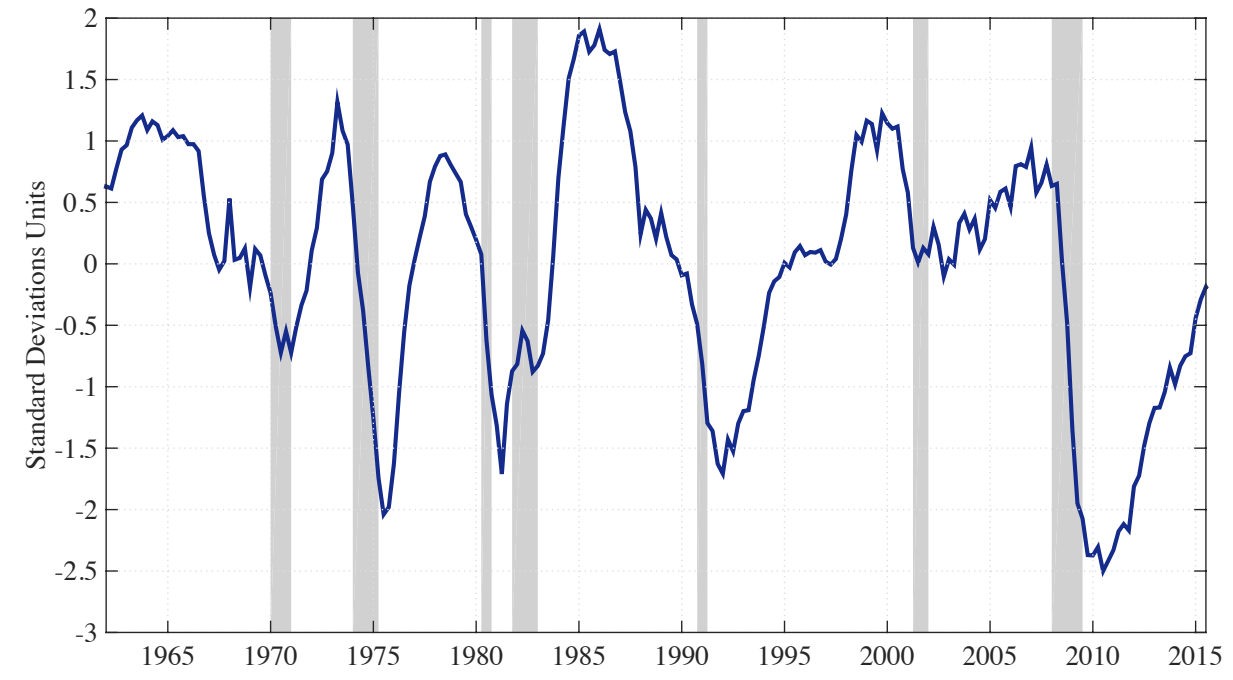

Note: The shaded gray areas are recessions as defined by the NBER.

We choose to capture the resilience of the financial system by constructing a synthetic measure. The latter is a weighted average of variables related to the balance sheets and funding methods of the main US economic agents (households, non financial corporations and financial corporations). A detailed description of the underlying data used for the construction of the indicator is offered in the appendix. The synthetic measure is estimated using a dynamic factor model. Specifically, we use an iterative method based on the Expectation-Maximization algorithm to estimate the weight associated with each variables (see Stock and Watson (2002) and Brave and Butters (2012)). 
Figure 1 displays the resulting (standardized) indicator. Positive values indicate higher levels of risk-tolerance, credit supply and indebtedness than on average. By contrast, negative index values means lower levels than on average. The series is clearly pro-cyclical, i.e. known periods of economic expansion correspond closely with increasingly positive index values. It is also worth noting that the turning points of the index usually lead changes in economic conditions. Remarkably, most of NBER recession dates are leaded by our risk sensitivity indicator.

\section{The ECONOMEtric Methodology}

We rely on a logistic vector smooth transition autoregressive (LVSTAR) model (Terasvirta et al., 2010) in order to capture the nonlinear relationships between the financial and real sides of the economy. The specification is given by

$$
X_{t}=A_{0}+\sum_{j=1}^{q}\left[A_{j}+G\left(d_{t}\right) B_{j}\right] X_{t-j}+u_{t},
$$

where $X_{t}$ is an $m \times 1$ vector, $A_{0}$ is an $m \times 1$ intercept vector, $A_{j}$ and $B_{j}, j=1, \ldots, q$, are $m \times m$ parameter matrices, $u_{t}$ is a vector of canonical innovations with zero mean, and covariance matrix given by $\Sigma_{u}$, and

$$
G\left(d_{t}\right)=\operatorname{diag}\left[G_{1}\left(d_{t}\right), \cdots, G_{m}\left(d_{t}\right)\right],
$$

is an $m \times m$ diagonal matrix of logistic transition functions

$$
G_{i}\left(d_{t}\right)=\left[1+\exp \left\{-\frac{\gamma_{i}}{\sigma_{d}}\left(d_{t}-\bar{d}\right)\right\}\right]^{-1},
$$

for $i=1, \ldots, m . \gamma_{i}>0$, and $\bar{d}_{t}$ is the long run average of the transition variable $d_{t}$. By construction, the transition function $G_{i}\left(d_{t}\right)$ is bounded between 0 and 1 . When $G\left(d_{t}\right)=0$, the LVSTAR model becomes a linear vector autoregressive model (VAR) with parameters $A_{j}$. In contrast, when $G\left(d_{t}\right)=1$, the LVSTAR model becomes a different VAR with parameters $A_{j}+B_{j}$. The smoothness of the transition from one extreme regime to the other is governed by the standardized parameter $\tilde{\gamma}_{i}=\gamma_{i} / \sigma_{d}$. The model is estimated by nonlinear least squares techniques (see Hubrich and Terasvirta (2013) for a complete exposition).

The vector $X_{t}$ includes the detrended US real gross domestic product per capita ${ }^{1}\left(Y_{t}\right)$, our risk sensitivity indicator $\left(F_{t}\right)$, and the shadow federal funds rate $\left(R_{t}\right)$ of $\mathrm{Wu}$ and $\mathrm{Xia}(2016){ }^{2}$ The data covers the period 1961Q1-2015Q3. The choice of the transmission variable $d_{t}$ in (1)-(3) is not innocuous. We restrict attention to three candidates: the backward-looking 4 quarters moving

\footnotetext{
${ }^{1}$ The cyclical component of real GDP per capita is obtained by fitting a linear and quadratic time trends to the log of the original series.

${ }^{2}$ The shadow rate is a summary measure of total accommodation provided by conventional and unconventional monetary policies. When policy rates are positive, it is identical to the federal funds rate. When the zero lower bound is breached, it is the rate that observed long-term interest rates would imply if the policy rate could be negative.
} 
averages of output, the risk sensitivity index and the monetary policy rate. After estimation, we evaluate key statistics (mean square error, sum of squares residuals and Theil's U-statistic) for each of these models, and select the one that shows greater accuracy. The results suggest that the moving average of output is the best candidate. In addition, our LVSTAR model includes two lags. ${ }^{3}$

We use the following usual strategy to identify monetary policy shocks. We denote $\varepsilon_{t}$ the vector of structural shocks whose variance are normalized to unity and they are mutually uncorrelated. Let the mapping between canonical innovations and structural shocks $u_{t}=S \varepsilon_{t}$ where $S$ is a $3 \times 3$ matrix. This matrix is obtained as the Cholesky decomposition of $\Sigma_{u}$. Given the ordering of variables in $X_{t}=\left[Y_{t}, F_{t}, R_{t}\right]^{\prime}$, monetary policy shocks have no contemporaneous impact on aggregate output and on financial conditions (Christiano et al. (1999)). We aim to isolate the direct effect of monetary policy shocks on output from the indirect effect operating through the risktaking behavior of economic agents. To this end, we construct hypothetical impulse responses to a policy shock keeping risk sensitivity fixed at all forecast horizons. A comparison of these hypothetical responses with the actual ones allows us to assess the importance of risk taking as a transmission mechanism of monetary policy shocks. ${ }^{4}$

\section{Dynamic Responses to MONetary POlicy SHOCKS}

The nonlinear impulse responses are computed for three different cases: (i) a "normal" regime, in which the initial conditions of output are associated with the $[40 \%-60 \%]$ percentiles of its empirical distribution, (ii) an "expansion" regime, in which the initial conditions of output are selected from the top $20 \%$ percentiles, and (iii) a "recession" regime, in which the initial conditions of output are selected from the bottom $20 \%$ percentiles.

Figure 2 displays the generalized impulse response functions of the model to a monetary policy shock, associated with the three above cases. ${ }^{5}$ Solid lines represent the impulse responses to a one-standard deviation expansionary monetary policy shock in the LVSTAR model. Dotted lines show the hypothetical impulse responses holding the response of risk sensitivity fixed at zero. Dashed lines describe the results for the corresponding linear VAR model.

\footnotetext{
${ }^{3}$ We conduct some misspecification tests (system stability, neglected serial correlation, structural change, normality of innovation) on the estimated model and we do not find any evidence against it.

${ }^{4}$ To make risk sensitivity unresponsive to a change in monetary policy, we create a hypothetical sequence of risk sensitivity shocks which cancels the response of the indicator, so that it is zero at each point in time (see Bachmann and Sims (2012) for a detailed exposition of the methodology).

${ }^{5}$ The generalized impulse response functions are computed according to Koop et al. (1996).
} 
Figure 2. Dynamic Effects of an Expansionary Policy Shock

(a) Normal Times
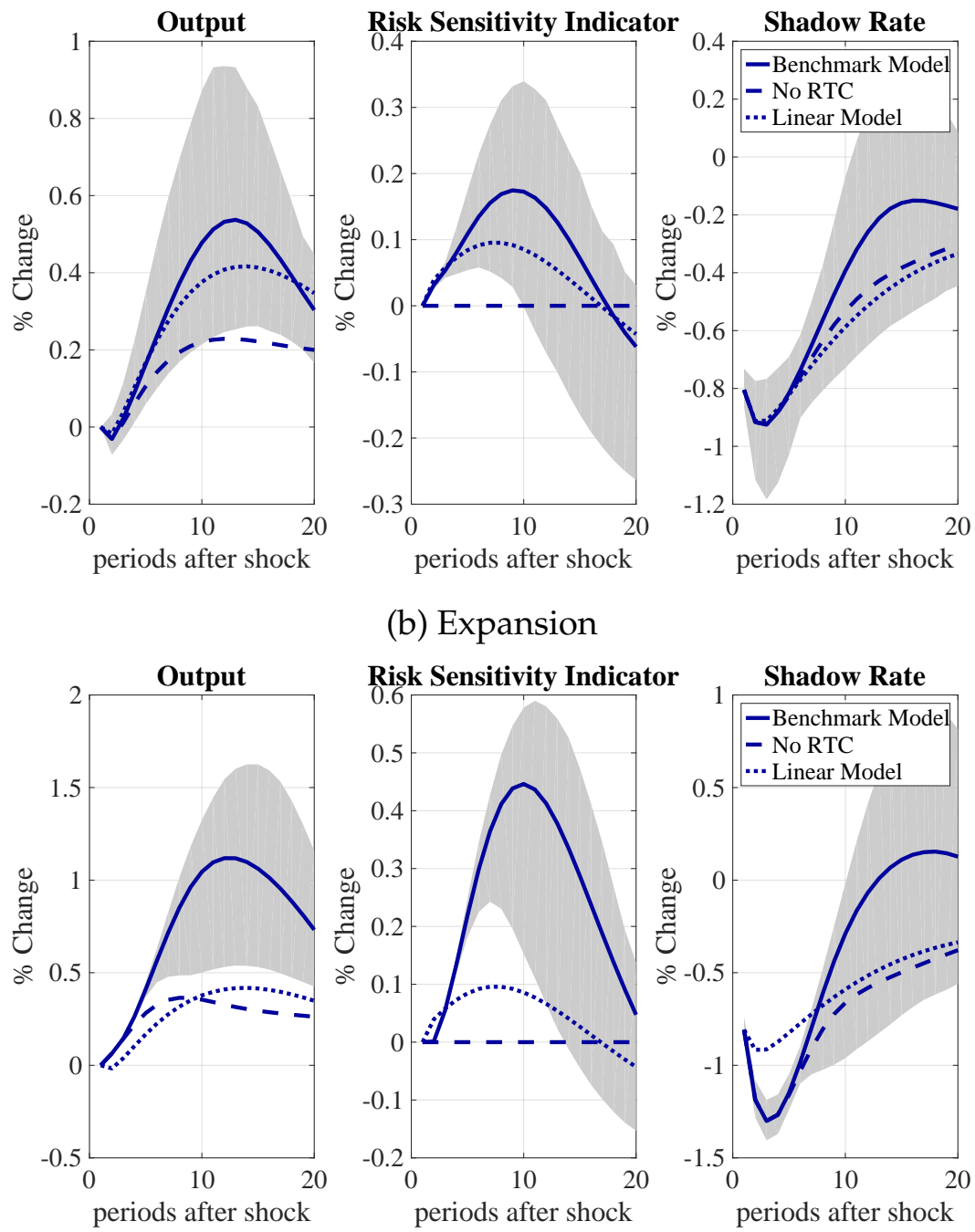

(b) Expansion
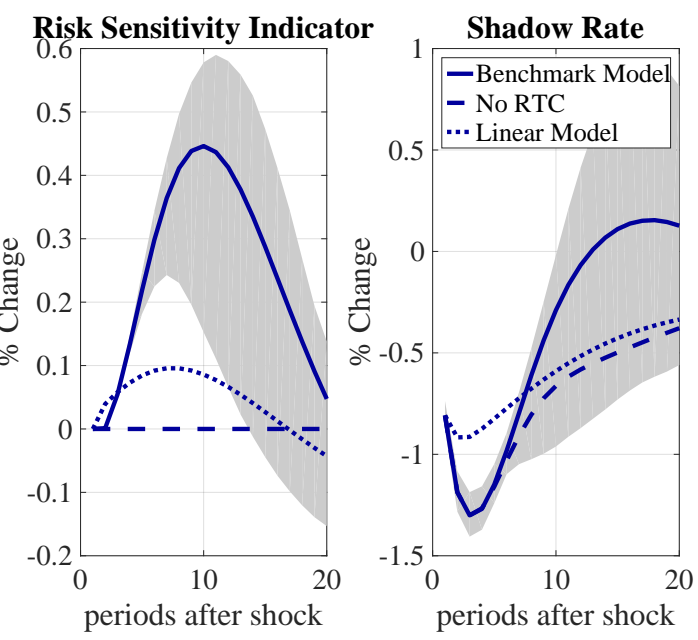

(c) Recession
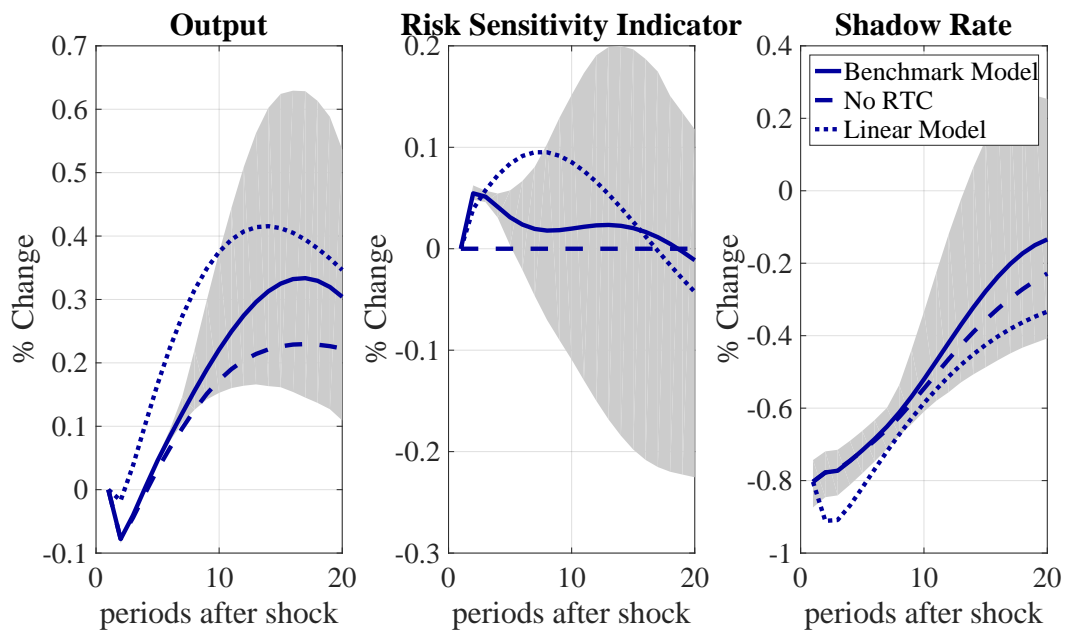

Note: Solid lines: benchmark model. Dotted lines: no risk-taking channel (RTC). Dashed lines: linear VAR model. Gray shaded areas are the $90 \%$ confidence intervals of the benchmark model. 
Two major findings are obtained. First, in normal times the nonlinear impulse responses are very similar to those estimated in the linear model. However, this is no true in extreme states, particularly during expansions. The solid lines show that, while in recession output declines on impact before rising slightly a few quarters later, in an economic expansion it rises significantly and remains persistently well above zero. As for risk sensitivity, the impact of the shock is much stronger in the expansion regime.

Second, the behavior of output without the endogenous response of risk taking is lower than in the benchmark model whatever the regime. This suggests a positive role of risk taking in the transmission of monetary policy. However, the impulse responses are strongly state-dependent. In the expansionary regime the difference between the hypothetical and actual output response is large. In contrast, in the low and normal growth regimes the difference is economically small and statistically insignificant. This corroborates the notion that the risk-taking channel is far from being the most important transmission channel of monetary policy. However, during booms when risk is underestimated, the buildup of risks can amplify significantly business fluctuations and increase macroeconomic volatility, as advocated by Borio and Zhu (2012).

To quantify these findings, Table 1 presents two measures of the effect of monetary policy shocks on output: (i) the maximum response of output over a 20 quarter horizon, called max effect, and (ii) the sum over the same time horizon of the output response, called cumulative effect. As expected, the effect of the shock in a normal regime is very similar to that estimated in the linear model. By contrast, in expansion the effect is much larger. In particular, both the max and cumulative effects are almost three times as large than in the linear specification. In recession, these effects are substantially smaller. The bottom panel of Table 1 summarizes the response of output when risk sensitivity is held fixed at zero. Both the max and cumulative responses of output are larger in the expansion regime. Nonetheless, the differences across regimes are much smaller than in the benchmark specification. This highlights, once again, the importance of a risk-taking behavior during economic booms.

Table 1. The Effects of Monetary Policy Shocks on Output

\begin{tabular}{lcccc}
\hline \hline & Linear model & Normal times & Expansion & Recession \\
\hline Benchmark specification & & & & \\
Max effect & 0.41 & 0.50 & 1.18 & 0.33 \\
Cumulative effect & 5.75 & 6.14 & 15.6 & 3.79 \\
Isolating risk sensitivity & & & & \\
Max effect & - & 0.22 & 0.36 & 0.23 \\
Cumulative effect & - & 3.13 & 5.36 & 2.66 \\
\hline
\end{tabular}




\section{CONCLUSION}

In this paper, we provide evidence that the role of the risk-taking channel depends on the state of the economy. During economic booms, the risk-taking channel of monetary policy has an amplifying effect on output. It is therefore important for central banks to take this channel into account when adjusting their policy in order not to exacerbate boom-bust patterns and accommodate the buildup of financial imbalances.

\section{REFERENCES}

Ampudia M, van Vlokhoven H, Zochowski D. 2016. Financial fragility of euro area households. Journal of Financial Stability 27: 250-262. ISSN 1572-3089.

Bachmann R, Sims ER. 2012. Confidence and the transmission of government spending shocks. Journal of Monetary Economics 59: 235-249. ISSN 0304-3932.

Bernstein S, Lerner J, Mezzanotti F. 2017. Private Equity and Financial Fragility during the Crisis. Working Paper 23626, National Bureau of Economic Research. DOI: 10.3386/w23626.

Borio C, Zhu H. 2012. Capital regulation, risk-taking and monetary policy: A missing link in the transmission mechanism? Journal of Financial Stability 8: 236-251.

Brave S, Butters RA. 2012. Diagnosing the Financial System: Financial Conditions and Financial Stress. International Journal of Central Banking 8: 191-239.

Christiano LJ, Eichenbaum M, Evans CL. 1999. Monetary policy shocks: What have we learned and to what end? In Handbook of Macroeconomics, volume 1, Part A. Elsevier, 65-148.

Diamond DW, Rajan RG. 2012. Illiquid Banks, Financial Stability, and Interest Rate Policy. Journal of Political Economy 120: 552-591. ISSN 0022-3808.

Hatzius J, Hooper P, Mishkin FS, Schoenholtz KL, Watson MW. 2010. Financial Conditions Indexes: A Fresh Look after the Financial Crisis. Working Paper 16150, National Bureau of Economic Research. DOI: 10.3386/w16150.

Hubrich K, Terasvirta T. 2013. Thresholds and Smooth Transitions in Vector Autoregressive Models. Technical Report 2013-18, Department of Economics and Business Economics, Aarhus University.

Koop G, Pesaran MH, Potter SM. 1996. Impulse response analysis in nonlinear multivariate models. Journal of Econometrics 74: 119-147.

Stock JH, Watson MW. 2002. Forecasting Using Principal Components from a Large Number of Predictors. Journal of the American Statistical Association 97: 1167-1179. ISSN 0162-1459.

Terasvirta T, Tjostheim D, Granger CWJ. 2010. Modelling Nonlinear Economic Time Series. Oxford University Press. 
Tullio J, Marco P, Marco DM. 2013. Households' indebtedness and financial fragility. Journal of Financial Management, Markets and Institutions : 23-46.

Wu JC, Xia FD. 2016. Measuring the Macroeconomic Impact of Monetary Policy at the Zero Lower Bound. Journal of Money, Credit and Banking 48: 253-291. ISSN 1538-4616.

APPENDIX: INFORMATION UNDERLYING THE RISK SENSITIVITY INDICATOR

Table A1. Description of Financial Variables by Economic Sector

\begin{tabular}{lcc}
\hline \hline Financial Indicator & Source & Period \\
\hline Households & & \\
Debt service payments to disposable personal income & BIS & 1980Q1-2015Q3 \\
Net worth & FA & 1961Q1-2015Q3 \\
Total liabilities & FA & 1961Q1-2015Q3 \\
Nonfinancial Corporate Business & & \\
Net worth & FA & 1961Q1-2015Q3 \\
Total liabilities & FA & 1961Q1-2015Q3 \\
Short-term liabilities to total liabilities & FA & 1961Q1-2015Q3 \\
Interest service ratio & FA & 1961Q1-2015Q3 \\
Financial Business & & \\
Total equity capital & FA & 1961Q1-2015Q3 \\
Total liabilities & FA & 1961Q1-2015Q3 \\
Short-term liabilities to total liabilities & FA & 1961Q1-2015Q3 \\
Total financial assets of shadow banks & FA & 1961Q1-2015Q3 \\
Additional Financial Indicators & & \\
Total credit to private non-financial sectors & BIS & 1961Q1-2015Q3 \\
Residential property prices & BIS & 1975Q4-2015Q3 \\
\hline
\end{tabular}

Note: We use the quarterly annual growth rate of each financial indicator. BIS stands for Bank for International Settlements. FA denotes the Financial Accounts of the US. All variables are in real terms. Interest Service Ratio is equal to the net operating surplus plus interest received, divided by interest paid. These three variables are only available at annual frequency. We use cubic spline interpolation to disaggregate annual data to quarterly series. Shadow banks include ABS issuers, finance companies and funding corporations. 